\title{
ALGORITHMIC TRADING AND EFFICIENCY OF THE STOCK MARKET IN POLAND
}

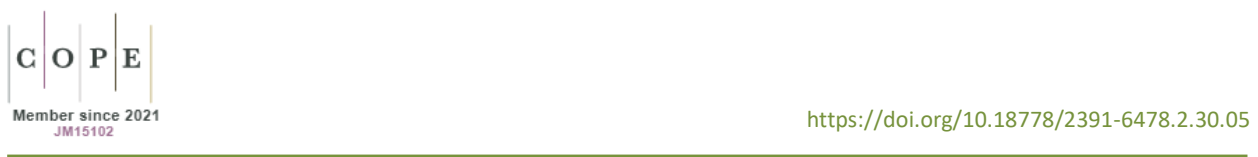

\author{
Rafał Jóźwicki ${ }^{*}$ Paweł Trippner ${ }^{* *}$, Karolina Kłos ${ }^{* * *}$
}

\begin{abstract}
The aim of the article is to investigate the impact of algorithmic trading on the returns obtained in the context of market efficiency theory. The research hypothesis is that algorithmic trading can contribute to a better rate of return than when using passive investment strategies. Technological progress can be observed in many different aspects of our lives, including investing in capital markets where we can see changes resulting from the spread of new technologies.

The methodology used in this paper consists in confronting a sample trading system based on classical technical analysis tools with a control strategy consisting in buying securities at the beginning of the test period and holding them until the end of this period.

The results obtained confirm the validity of the theory of information efficiency of the capital market, as the active investment strategy based on algorithmic trading did not yield better results than the control strategy.
\end{abstract}

Keywords: algorithmic trading, market efficiency, trading system, investing, technical analysis.

JEL Class: E22, E44, G11, G31.

\footnotetext{
* Ph.D., Institute of Finance, University of Lodz; https://orcid.org/0000-0002-4346-4046.

** Ph.D. University Professor, Institute of Finance, University of Social Sciences; https://orcid.org/0000-0003-1060-517X.

${ }^{* * *} \mathrm{MSc}$, Owner of Finance and Insurance Center.
} 


\section{INTRODUCTION}

The development of technology observed nowadays has a significant impact on many areas of our functioning. Undoubtedly, one of them is how we trade on stock exchanges and other markets which offer investors an opportunity to engage capital. Internet access or specialized software considerably change and expand investment horizons. Nowadays, placing orders in person at a brokerage office or via a classic phone is really rare as long as we talk about investors actively managing their capital. Such orders can be placed on the basis of various types of brokerage investment accounts allowing a player to view the quotes in real time together with various technical indicators in the chart, or the possibility to view the quotes in parallel at different intervals (daily, hourly, or any minute chart), exchange arbitrage, high frequency - trading and the option to view the order book.

This gives an investor an opportunity to view their placed and executed orders and also those of other players in real time. All of this, taken together, obviously, offers a wider range of possibilities for active capital management than some years ago. The fact that the technology has dramatically increased investors' access to information affecting stock market prices is also significant. Web portals and services outdo each other in providing news, which, yet, may have a negative impact when it comes to making decisions on the execution of transactions. To some extent this may be due to the emotions accompanying the stock market game.

A good solution to the problem of the influence of these emotions on decision making is the possibility of using automatic transaction systems. By this notion we understand the algorithm created and implemented, which, on the basis of the set criteria, purchases and sells selected financial instruments. The exchange game takes place practically without the participation of an investor, whose role boils down only to switching on the machine. Thus, emotions accompanying the transaction are completely eliminated. Everything is done on the basis of decision-making algorithms defined by the investor.

The contemporary use of algorithms and neural networks is very wide, one can risk saying that new areas of application are emerging on an ongoing basis, and so far these techniques are used not only in stock market forecasting, but also in medical and biological research, data analysis, economic forecasting, among others (Alma et al., 2019).

Another aspect of this issue is market efficiency, i.e. the theory that it is not possible to achieve a rate of return „,better than the market” by relying on historical information when making decisions about buying and selling financial instruments. However, taking into account the possibility of eliminating emotions interfering with the decision making processes, it is worthwhile to make an 
analysis that can solve the issues of the impact of automatic trading on the possible rates of return in the context of market efficiency.

Taking into account the above considerations, the aim of this article is to examine the impact of algorithmic trading on the obtained rates of return in the context of market efficiency theory.

The research assumes the hypothesis that the use of automated trading systems may contribute to obtaining returns „better than the market”, i.e. more favourable than the so - called ,control strategy".

The rationale for such analyses is the fact that within the scope of the subject of this article it is difficult to find scientific studies that would explore this issue in a way that takes into account the use of algorithmic trading. Of course, the stock exchange market in Poland has been analyzed many times in terms of effectiveness in its various forms, but the approach to this issue was of a different nature than in the present study. As far as the literature on this subject is concerned, two studies are worth noting in particular. The first one was related to the evaluation of the use of so-called technical tools (averages and oscillators), and the results obtained indicated that these methods do not give above-average and statistically significant rates of return (Czekaj et al., 2001: 75). In turn, the second study noted that the stock market in Poland was not effective in its initial phase of development. In the following years of its functioning, however, no attitude was found to reject a weak form of information effectiveness (Szyszka, 2003: 48).

\section{ALGORITHMIC TRADING}

An algorithm is a kind of „recipe" that leads to a step-by-step solution to a problem, while algorithmics is a field of science that deals with algorithms and their properties (Sysło, 2016: 13-14).

The algorithmic trading itself is the area of using computers to execute a certain set of instructions to make a transaction in order to generate profits. The feature that characterizes such an action is undoubtedly the speed and frequency, which are impossible for an investor placing orders manually. Defined sets of rules, on the basis of which transactions are executed, are generally based on prices, quantities and turnovers in relation to the instrument itself, or on selected indicators of the describing instrument.

Of course, nothing stands in the way of using any mathematical models in this area. For example, the investor will define the program to buy if the price of the instrument exceeds the average of the set value, and the oscillator level is below the defined value. This means that the system will automatically track the instrument price and the average with the oscillator and place a buy order once the 
predefined conditions are met. For the investor it means that it is not necessary to constantly observe the prices and charts, or place orders on its own. The algorithmic trading system does this for the investor and places orders, provided that the conditions defined in the system are met.

Currently, the most common algorithmic trading machines used by traders were created in MQL language. MQL 4 is the language used to create advisors, also known as mechanical trading systems (Expert Advisors) (mql4.com). Thanks to its use, a stock exchange player does not have to be a programming specialist because the construction of market rules is done by using ready-made modules, by means of which the whole system is created. The MQL language itself is based on the $\mathrm{C}++$ language that is very popular among programmers.

The use of algorithmic trading undoubtedly has many advantages. The first one is the elimination of the influence of emotions on the decisions made. Everywhere where money is at stake, there are factors of human emotions, which can negatively influence the decision making process. Thanks to programming of market rules, these emotions are eliminated because a computer program works only on the basis of a specific algorithm. The second unquestionable advantage of algorithmic trading is the speed of the actions.

A human needs time to react on the basis of the received signals, which in combination with the aforementioned emotions may lead to a delay in placing an order, which, especially for very active players who are conducting intra-day trading (multiple transactions during one session, often with the same instrument) may have a significantly negative impact. Another advantage of algorithmic trading is the higher efficiency of data processing. A computer program in a given unit of time can analyze more data and make better decisions than a human being. Thanks to that, it is possible to construct transaction systems taking into account much more batch data than if it is the man himself who would like to process such data and execute transactions based on the received signals. In addition, some attention should be paid to the aspect of the possibility to play on foreign markets, which are active at night in local time. The investor can benefit from the possibility of trading while sleeping. Of course, algorithmic trading also has disadvantages. Trading on the stock markets is more than just signals generated from the batch data. Particularly experienced investors can point to a factor that is a certain sense of the market and a broader perspective on the transaction than just a mechanical action. Let us also point out that the system is only a computer program and a device that can fail. Unfortunately, the technique is unreliable, and if the failure happens at an unfortunate moment for the investor, it may mean a risk of severe losses.

Using algorithmic trading for trading on stock markets has positive and negative aspects, as well as opportunities and threats. This makes it reasonable to apply a SWOT analysis to evaluate this solution. 
Strengths:

- algorithmic trading is devoid of the influence of emotions on the transactions,

- transactions is less time-consuming for the trader than executing them manually,

- makes it possible to take full advantage of long market trends,

- makes it possible to trade in foreign markets during night hours.

Weaknesses:

- random price changes result in unfavorable trades.

Opportunities:

- can be used when new financial instruments appear on the market,

- transactions are executed immediately after the signal, which may give an advantage over other traders.

Threats:

- the trading algorithm may lose its effectiveness,

- a badly constructed algorithm may generate losses.

The presented aspects of the SWOT analysis indicate that the use of algorithmic trading from the investors' point of view is attractive when confronted with traditional trading.

It is also worth noting that the algorithmic trade can be further enriched and extended with elements of new artificial intelligence methods e.g. fuzzy sets (Starczewski et al., 2020), neural networks (Bilski et al., 2020), particle swarm optimization (Dziwiński et al., 2020), rough support vector machines (Nowicki et al., 2019) or perhaps so-called ensemble techniques (Homenda et al., 2020).

\section{MARKET INFORMATION EFFICIENCY AND ITS CONSEQUENCES}

Fama presented a general hypothesis of an efficient market (Efficient Market Hypothesis, EMH), however, this efficiency may take different forms depending on the type of information reaching investors. The first group of information is related to historical share prices, rates of return and trading volumes. These are the data which inform about the course of transactions concluded so far during stock exchange sessions. It is assumed that if the price fully reflects this information, the market is effective in the so-called weak form. The hypothesis of poor information effectiveness of the capital market says that any historical data included in the mentioned group of information will not allow for obtaining above-average rates of return in the long run, and future values of the price are in no way related to their previous volumes. The basic methods of assessing whether the market is effective in the sense of a weak hypothesis are statistical tests and technical analysis tools used to create so-called market rules (Fama, 1970). 
The second group of information used by investors is wider and includes those that are included in the first group and all other publicly available information in the form of financial statements, analyses and recommendations, macroeconomic data and others. It is assumed that if this information is reflected in the price, the market is effective in the sense of the semi-powerful hypothesis. This hypothesis covers the weak hypothesis, which means that if the market is effective in the sense of the semi-powerful hypothesis, it is also effective in the sense of the weak hypothesis. The implication of this hypothesis is that the use of historical data based on all possible sources of information available to the public will not allow for above average rates of return in the long run. It is assumed that the information included in the second group is also not in any way related to future value prices. This also means that the use of methods taking into account this information, including fundamental analysis methods, is not justified.

The third group of information includes all possible available public information and non-public information, known only to persons involved in the functioning of the entity, for example, members of the company's authorities, brokers, investment advisors and other persons closely related to the company and the market. The hypothesis of the so-called strong effectiveness implies that using this particular group of information also in the long run will not allow to obtain an above-average rate of return. The price of the value takes into account all possible publicly available and non-public information.

\section{TECHNICAL ANALYSIS TOOLS AND CREATION OF TRANSACTIONAL RULES}

Technical analysis is a group of methods and tools based on historical data concerning market quotations of particular assets. It is based on charts that enable to read on the basis of some characteristic forms of future market behaviors. In addition, on the basis of historical data, various types of indicators are calculated, also using the possibility of placing them in the chart together with the quotations of a given instrument. The literature of the subject provides investors with a large number of possible indicators, however, they are generally divided into three basic categories. They include trend indicators, oscillators and mood indicators (Murphy, 2019).

Trend indicators, according to their name, allow traders to determine what kind of trend we are dealing with at a given time. The most popular in this respect are mainly moving averages based on different calculation formulas and the MACD (Moving Average Convergence Divergence) indicator by Gerald Appel (2005). Using these tools a trader can determine whether at a given moment in a given time horizon, we are dealing with an upward, downward trend or a lateral movement. Oscillators, on the other hand, allow for short-term determination of the so-called overbought or oversold market. 
Signal lines are plotted on the graph, which indicates these levels. Mood indicators will allow you to determine how optimistic or pessimistic investors' attitudes are by examining various groups directly related to the market. Technical tools used to create market rules to test the information efficiency hypothesis in the weak sense are used individually or in combination. When creating a system, an investor has to make some important decisions concerning, for example, what investment horizon they are interested in, what size of the occupied position will be, but the most important are the rules of opening and closing a position, i.e. the rules of buying and selling financial instruments they are interested in. According to the hypothesis of information efficiency of the market in the weak sense, investors creating trading rules may compare them with the control strategy consisting in buying and maintaining a given financial instrument for a certain period of time. If it turns out that the rate of return on an active strategy based on technical analysis tools is more advantageous than the rate of return obtained in a passive strategy, it would mean that historical information has an impact on the possibility of obtaining above-average rates of return in the future, which in turn would mean that there is no basis for the hypothesis of poor market efficiency.

\section{CALCULATION METHODOLOGY AND RESULTS OBTAINED}

The subject of analysis in this study was the WIG20 index in 2018-2019. The study divided this period into two sub-periods. The first one, i.e. the year 2018 was used for so-called system optimization. The second sub-period, i.e. 2019, was used to carry out tests using the parameters obtained in the year of system optimization. Such an approach is connected with the fact that in the era of computer computing techniques, it is quite easy to determine, based on historical data, what the parameters for particular indicators should be in order to demonstrate the lack of market efficiency. In reality, however, investors do not play on historical data, but on the current ones. This is the reason why such an approach was used - the values of parameters for indicators were determined and then used in the "future" period in order to obtain similarly attractive rates in relation to the control strategy. Dividing the research period into control and optimization is an objective approach to the application of such parameters in order to assess their impact on the actual effectiveness of transaction rules.

The analyses also make other assumptions based on market realities: the commission for buying and selling is $1 \%$, the funds not involved in the transaction bear interest at a risk-free rate of 3\% (the system does not recommend maintaining an open position in certain periods), and only share purchases are possible on the market, i.e. there is no possibility of using the so-called short sale. 
The trading rules use trend indicators (a single moving average, two moving averages and MACD) and oscillators (RSI and stochastic). Table 1 and 2 show the results of optimization in 2018 and tests for trend indicators and oscillators in 2019.

Table 1. Optimization of parameters and their testing with the use of investment strategies based on trend indicators for WIG index-20 in 2018-2019

\begin{tabular}{|c|c|c|c|}
\hline \multicolumn{3}{|r|}{ Specification } & Parameter \\
\hline \multirow{14}{*}{ 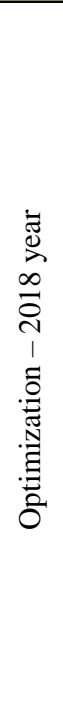 } & \multirow{4}{*}{ 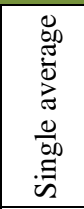 } & Average length & 55 \\
\hline & & Max loss [\%] & 12,08 \\
\hline & & Annual profitability of the strategy [\%] & 5,89 \\
\hline & & The difference between active and passive strategies [p.p.] & 13,39 \\
\hline & \multirow{5}{*}{ 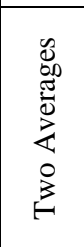 } & Short average length & 23 \\
\hline & & Long average length & 79 \\
\hline & & Max loss [\%] & 9,25 \\
\hline & & Annual profitability of the strategy [\%] & 10,55 \\
\hline & & The difference between active and passive strategies [p.p.] & 18,05 \\
\hline & \multirow{4}{*}{ 己ి } & Average signal length & 17 \\
\hline & & Max loss [\%] & 19,68 \\
\hline & & Annual profitability of the strategy [\%] & 6,34 \\
\hline & & The difference between active and passive strategies [p.p.] & 13,84 \\
\hline & & Annual profitability of the passive strategy [\%] & $-7,50$ \\
\hline \multirow{7}{*}{ 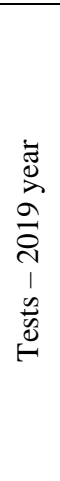 } & \multirow{2}{*}{ 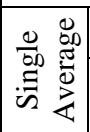 } & Annual profitability of the strategy [\%] & $-11,58$ \\
\hline & & The difference between active and passive strategies [p.p.] & $-6,02$ \\
\hline & \multirow{2}{*}{ 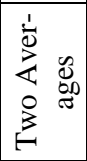 } & Annual profitability of the strategy [\%] & $-9,28$ \\
\hline & & The difference between active and passive strategies [p.p.] & $-3,72$ \\
\hline & \multirow{3}{*}{ 导 } & Annual profitability of the strategy [\%] & $-12,95$ \\
\hline & & The difference between active and passive strategies [p.p.] & $-7,39$ \\
\hline & & Annual profitability of the passive strategy [\%] & $-5,56$ \\
\hline
\end{tabular}

Source: own calculations. 
Table 2. Optimization of parameters and their testing with the use of investment strategies based on oscillators for WIG index-20 in 2018-2019

\begin{tabular}{|c|c|c|c|}
\hline \multicolumn{3}{|r|}{ Specification } & Parameter \\
\hline \multirow{12}{*}{ 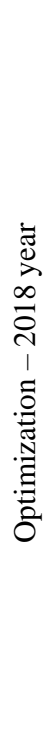 } & \multirow{5}{*}{ 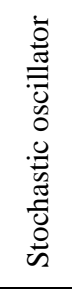 } & Overtaking & 19 \\
\hline & & Buyout & 92 \\
\hline & & Max loss [\%] & 11,28 \\
\hline & & Annual profitability of the strategy [\%] & 3,12 \\
\hline & & $\begin{array}{l}\text { The difference between active and passive strategies } \\
\text { [p.p.] }\end{array}$ & 10,62 \\
\hline & \multirow{6}{*}{ 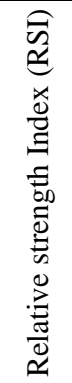 } & RSI length & 26 \\
\hline & & Overtaking & 19 \\
\hline & & Buyout & 88 \\
\hline & & Max loss [\%] & 35,34 \\
\hline & & Annual profitability of the strategy [\%] & 11,28 \\
\hline & & $\begin{array}{l}\text { The difference between active and passive strategies } \\
\text { [p.p.] }\end{array}$ & 18,78 \\
\hline & & Annual profitability of the passive strategy [\%] & $-7,50$ \\
\hline \multirow{5}{*}{ 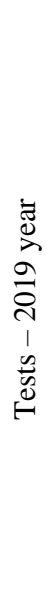 } & \multirow{2}{*}{ 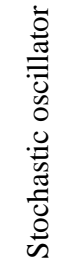 } & Annual profitability of the strategy [\%] & $-16,57$ \\
\hline & & $\begin{array}{l}\text { The difference between active and passive strategies } \\
\text { [p.p.] }\end{array}$ & $-11,01$ \\
\hline & \multirow{2}{*}{ 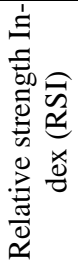 } & Annual profitability of the strategy [\%] & $-13,49$ \\
\hline & & $\begin{array}{l}\text { The difference between active and passive strategies } \\
\text { [p.p.] }\end{array}$ & $-7,93$ \\
\hline & \multicolumn{2}{|r|}{ Annual profitability of the passive strategy [\%] } & $-5,56$ \\
\hline
\end{tabular}

Source: own calculations. 
The data in the tables are divided into two sections: data optimization and tests for the obtained parameters. In the data optimization section it was checked what value of parameters for particular indicators in 2018 would give the highest rate of return. This section also presents the rate of return on the chosen strategy and its comparison to the buy and hold control strategy, i.e. the rate of return on WIG20 index in 2018. In the test section, the profitability of the strategy was checked on the obtained parameters using the parameters of indicators at the level of values obtained in the optimization section. This allows for an objective assessment of whether historical data can be successfully used in future investment decisions.

\section{CONCLUSIONS}

The analyses carried out have led the authors to formulate several conclusions. First of all, referring to the hypothesis set at the beginning of the paper, it should be noted that relying on a constructed trading system in investment decisions does not allow to obtain better investment results in the examined periods than the control strategy, i.e. relying on algorithmic trading does not bring the intended results. This, in turn, means that in the examined period we had to deal with the information effectiveness of the market in the form of a weak hypothesis. It is also noteworthy that during the tests on data in 2018 it was possible to obtain a better rate of return than the market rate for each technical tool. However, this is explained by the fact of optimizing historical data, for which it is possible and easy to select a better parameter than the market one. For 2019, which is the test period for the parameters obtained for optimization in 2018, for each technical indicator a result worse than the control strategy was obtained. These values in Table 1 and 2 are placed in the row „difference between active and passive strategy”. It proves that relying on historical data does not allow obtaining in the long run a rate of return better than the market one, which confirms the correctness of the market information effectiveness hypothesis.

The volume of the study is too small to generate conclusions for all trading systems based on algorithmic trading. Undoubtedly, this study area requires further and in-depth research, all the more so because basing the stock market game on trading machines is becoming more and more important and is an increasingly common phenomenon. 


\section{REFERENCES}

Alma, Y. Alanis, Arana-Daniel, N., Lopez-Franco, C., eds. (2019). Artificial Neural Networks for Engineering Applications, Elsevier.

Appel, G. (2005). Technical Analysis: Power Tools for Active Investors. New York: Pearson Education Inc.

Bilski, J., Kowalczyk, B., Marchlewska, A., Zurada, J.M. (2020). Local Levenberg-Marquardt Algorithm for Learning Feedforwad Neural Networks. Journal of Artificial Intelligence and Soft Computing Research, 10(4).

Czekaj, J., Woś, M., Żarnowski, J. (2001). Efektywność giełdowego rynku akcji w Polsce. Z perspektywy dziesięciolecia. Warszawa: Wydawnictwo Naukowe PWN.

Dziwiński, P., Bartczuk, Ł., Paszkowski, J. (2020). A New Auto Adaptive Fuzzy Hybrid Particle Swarm Optimization and Genetic Algorithm. Journal of Artificial Intelligence and Soft Computing Research, 10(2).

Fama, E.F. (1970). Efficient Capital Markets: A review of Theory and Empirical Work. Journal of Finance, 2.

Homenda, W., Jastrzębska, A., Pedrycz, W., Fusheng, Y. (2020). Combining Classifiers for Foreign Pattern Rejection, Journal of Artificial Intelligence and Soft Computing Research, 10(2).

mq14.com, www.mq14.com [Accessed: 4.11.2020].

Murphy, J.J. (2019). Technical Analysis of the Financial Markets: A Comprehensive Guide to Trading Methods and Applications. New York: New York Institute of Finance.

Nowicki, R.K., Grzanek, K., Hayashi, Y. (2019). Rough Support Vector Machine for Classification with Interval and Incomplete Data. Journal of Artificial Intelligence and Soft Computing Research, 10(1).

Starczewski, J.T., Goetzen, P., Napoli, Ch. (2020). Triangular Fuzzy-Rough Set Based Fuzzification of Fuzzy Rule-Based Systems. Journal of Artificial Intelligence and Soft Computing Research, $10(4)$.

Sysło, M.M. (2016). Algorytmy (Algorithms). Gliwice: Wydawnictwo HELION.

Szyszka, A. (2003). Efektywność gietdy papierów wartościowych $w$ Warszawie na tle rynków dojrzatych (Efficiency of the Warsaw Stock Exchange in comparison with mature markets). Poznań: Wydawnictwo Akademii Ekonomicznej w Poznaniu. 